\title{
DESEMPENHO DE CULTIVARES DE SOJA EM LATOSSOLOS VERMELHOS COM DIFERENTES CLASSES TEXTURAIS
}

\author{
Antônio José Meirelles Flores ${ }^{1}$, Carlos Sérgio Tiritan ${ }^{1}$, Gil Miguel de Sousa Câmara ${ }^{2}$, Hélio do \\ $\mathrm{Prado}^{3}$, Agnaldo Massao Sato ${ }^{4}$, Diego Henriques Santos ${ }^{5}$ \\ ${ }^{1}$ Universidade do Oeste Paulista - Presidente Prudente - SP - e-mail: tuca@ copasul.coop.br \\ ${ }^{2}$ Escola Superior de Agricultura "Luiz de Queiroz" - Piracicaba - SP \\ ${ }^{3}$ Instituto Agronômico, Centro de Cana IAC - Ribeirão Preto - SP \\ ${ }^{4}$ Cooperativa Agrícola Sul Matogrossense - Naviraí-MS \\ ${ }^{5}$ Companhia de Desenvolvimento Agrícola de São Paulo - Presidente Prudente - SP
}

\section{RESUMO}

Com o objetivo de avaliar o desempenho de cultivares de soja dos ciclos precoce, semiprecoce e médio em Latossolos Vermelhos com diferentes classes texturais, realizou-se experimento no município de Naviraí-MS, no ano agrícola 2008/2009. Adotou-se delineamento experimental em blocos inteiramente casualisados, com quatro repetições. Os cultivares de soja utilizados foram CD 202, CD 208 e CD 214RR de ciclo precoce, BRS 239, BRS CharruaRR e BRS 245RR de ciclo semiprecoce, além dos cultivares CD 219RR e Monsoy 8001 de clico médio. A semeadura foi realizada em novembro de 2008, em sistema de plantio direto sobre a resteva de milho. Foram avaliados os parâmetros número de vagens por planta, número de grãos por vagens, peso de mil grãos e produtividade. Independente da classe textural do solo, a fertilização e manutenção de médios a altos teores de nutrientes nos Latossolos Vermelhos Eutróficos de textura média a muito argilosa possibilita a expressão fenotípica de altas produtividades agrícolas de grãos pelas cultivares de soja.

Palavras-chave: Glycine max L., ambientes de produção, classes de solo, produtividade de soja

\section{PERFORMANCE OF SOYBEAN CULTIVARS IN DIFFERENT SOIL CLASSES}

\begin{abstract}
Soybean is considered the main crop in Brazil due to both volume production and income. Many factors have contributed to a good performance of this crop in this country, such as adaptability of cultivars to many regions. The objective of this research was to evaluate soybean performance of early, semi-early and intermediate maturity cultivars in a sandy loam, clayey and very clayey Eutrudox. The experiment was carried out in Naviraí-MS, São Francisco Farm, in 2008/2009. The experimental design was the completely randomized block with four replications. The following soybean cultivars were evaluated: a) Early maturity: CD 202, CD 208 and CD 214RR; b) Semi early maturity: BRS 239, BRS CharruaRR and BRS 245RR; and c) Intermediate maturity: CD 219RR and Monsoy 8001. Sowing was conducted over maize residues on November, 15, 2008 under no tillage system and $333 \mathrm{~kg} \mathrm{ha}^{-1}$ of fertilizer was applied. The number of pods per plant, number of grains per pod, weight of 1,000 grains and yield $\left(\mathrm{kg} \mathrm{ha}^{-1}\right)$ were evaluated. Fertilization and maintenance of intermediate-high nutrient levels in Eutrudox soils of any textures provided conditions for soybean cultivars to express high yield potentials.
\end{abstract}

Key words: Glycine max L., cropping conditions, soil textures, soybean yield 


\section{INTRODUÇÃO}

A soja (Glicine max L.) é uma das culturas de maior importância econômica do país. Na safra 2009/2010, a área semeada superou 23,5 milhões de hectares, com produção de 68,9 milhões de toneladas. No ano agrícola 2010/2011, a produção nacional cresceu 9,7\%, atingindo 75,32 milhões de toneladas Conab (2011). Fatores como melhoramento genético, manejo integrado de pragas, doenças e plantas daninhas, agricultura de precisão e logística de armazenamento e transporte têm contribuído para o bom desempenho da soja no Brasil Parra (2006).

Existe um grande número de fatores que relacionam a planta (cultivares) aos ambientes de produção (clima x solo) e ao manejo das lavouras (tecnologias de produção), que interferem diretamente de forma positiva ou negativa na produtividade agrícola Câmara et al., (2002).

Segundo Novais (2007), o solo, resultado do intemperismo das rochas, tem como função favorecer o crescimento das raízes, permitir trocas gasosas, receber e reter água e nutrientes, além de promover o equilíbrio entre percentual do volume da fração solida (matéria orgânica, óxidos e hidróxidos de ferro e alumínio, areia, argila e silte) e do espaço poroso, que determina o volume de ar e da solução do solo para o crescimento das plantas.

O Sistema Brasileiro de Classificação de Solos - SiBCS Embrapa (2006) é dividido em 13 ordens de solo, sendo eles Argissolo, Cambissolo, Chernossolo, Espodossolo, Gleissolo, Latossolo, Luvissolo, Neossolo, Nitossolo, Organossolo, Planossolo, Plintossolo e Vertissolo, divididos nas sub ordens Vermelho, Vermelho-amarelo e Amarelo. Os Latossolos, que ocupam mais de $50 \%$ do território brasileiro Oliveira (2008), são solos minerais, apresentando horizonte B latossólico imediatamente abaixo de qualquer tipo de horizonte A.
Apresentam avançado estágio de intemperismo e material coloidal com baixa capacidade de troca de cátions e baixos teores de minerais primários. A reserva de nutriente é reduzida, fato que não impede que sejam bastante produtivos se bem manejados Embrapa (2006).

As variações das condições químicas abaixo da camada arável dos Latossolos revelam-se significativas, pois podem ser eutróficos, mesotróficos, distróficos, mesoálicos, álicos, ácricos e alumínicos. São eutróficos quando na camada sub superficial destacam-se pelos elevados teores de soma de base ( $\mathrm{Ca}, \mathrm{Mg}, \mathrm{K}$ e Na). Nos mesotróficos os níveis de cálcio são relativamente altos e ao mesmo tempo os teores de alumínio baixo, ao contrário dos mesoálicos que possuem níveis de cálcio baixo e de alumínio alto sem atingir a condição de álicos. Entre ambas as condições ocorrem os solos distróficos. Os Latossolos ácricos apresentam reduzido potencial nutricional no horizonte $\mathrm{B}$, baixo teor de cálcio e reduzido teor de alumínio. São álicos se os níveis de alumínio são altos e os teores de cálcio muito baixos, mas quando apresentam a particularidade de possuir teores de cálcio muito reduzidos e alumínio extremamente altos são alumínicos Prado (2008).

De acordo com as classes texturais, nos Latossolos textura média tendendo a arenosa, LV-1 (Latossolo Vermelho 1), os teores de argila variam de 16 a $25 \%$, nos de textura média tendendo a argilosa, LV-2 (Latossolo Vermelho 2), os níveis de argila oscilam de 26 a $35 \%$ de argila, nos de textura argilosa, LV-3 (Latossolo Vermelho 3), variam de 36 a $60 \%$ de argila, e nos de textura muito argilosa, LV-4 (Latossolo Vermelho 4), os teores de argila superam 60\% Prado (2008).

Os componentes de produção da soja são de grande importância para o melhoramento genético dos cultivares de soja, pois os mesmos são utilizados na seleção indireta de plantas de soja mais 
produtivas Reis et al., (2002). Os componentes de produção primários são: número de vagens por planta, número de sementes por planta, número médio de sementes por vagens, peso de mil sementes e produção de grãos Castro (2008). Os componentes de produção sofrem influência das condições ambientais durante o ciclo reprodutivo e chegam a variar num mesmo cultivar até sete vezes de um ano para o outro Anand \& Torrie (1963).

No Brasil, as cultivares de soja são classificadas em cinco grupos de maturação, precoce, semiprecoce, médio, semitardio e tardio Sediyama et al., (2009). Para o Estado do Mato Grosso do Sul, segundo Embrapa (2008), os grupos de maturação são precoce (ciclo até 115 dias), semiprecoce (entre 116 e 125 dias), médio (126 a 140 dias) e semitardio (acima de 140 dias).

As interações entre planta, ambiente e manejo possuem poucos estudos no Brasil. $\mathrm{O}$ que se tem estudado quanto ao cultivo da soja são efeitos envolvendo: genótipos $\mathrm{x}$ locais Soldini (1993); genótipos $\mathrm{x}$ anos Gieco (1997); genótipos x locais x anos Toledo et al., (1990); Alliprandini et al., (1994); Laínez-Mejía (1996); genótipos x locais $\mathrm{x}$ anos $\mathrm{x}$ épocas de semeaduras Arantes (1979).

Arantes (1979) relata a importância do agrupamento de ciclos de maturação e Alliprandini et al., (1993) confirmam a interação significativa para ciclos de maturação $x$ locais $x$ anos, indicando que para a combinação entre locais e anos existe um ciclo de maturação com maior potencial produtivo. Conhecer o ciclo de maturação ajuda o produtor no planejamento da safra. As variações ambientais (doenças, pragas, chuvas excessiva, secas, efeitos do fotoperíodo) são levadas mais em consideração, com maior possibilidade de sucesso pelo agricultor Rocha \& Vello (1999).

Neste sentido, o trabalho objetivou avaliar o desempenho de cultivares de soja em Latossolo Vermelho Eutrófico Textura média, Latossolo Vermelho Eutrófico Textura argilosa e Latossolo Vermelho Eutrófico Textura muito argilosa, visando identificar os genótipos que melhor se adaptam a cada classe textural.

\section{MATERIAL E MÉTODOS}

O trabalho foi conduzido em área comercial produtora de soja, na Fazenda São Francisco, Naviraí-MS, localizada a $22^{\circ} 57^{\prime} 52,8^{\prime \prime}$ de Latitude Sul e $54^{\circ} 03^{\prime} 13,2^{\prime \prime}$ de Longitude Oeste, com 352 metros de altitude. O clima da região é classificado como mesotérmico úmido (Cwa) por Fietz \& Fisch (2008). Os dados pluviométricos e de temperatura máxima e mínima da safra 2008/2009, bem como a série histórica da região encontram-se na Figura 1.

$\mathrm{O}$ experimento foi conduzido em esquema fatorial $3 \times 8$, sendo três classes texturais de solos: a) Latossolo Vermelho Eutrófico textura média tendendo a argilosa (LVe-2); b) Latossolo Vermelho Eutrófico textura argilosa (LVe-3) e c) Latossolo Vermelho Eutrófico textura muito argilosa (LVe-4) e oito cultivares de hábitos de crescimento determinado, pertencentes aos seguintes grupos de maturação (Embrapa 2008): a) grupo precoce: CD 202; CD 208 e CD 214RR; b) grupo semiprecoce: BRS 239; BRS CharruaRR e BRS 245RR e c) grupo médio: Monsoy 8001 e CD 219RR. Cada experimento delineado em blocos ao acaso corresponde a uma classe textural de solo onde foram conduzidas oito cultivares (tratamentos) repetidas quatro vezes.

Cada unidade experimental constou de cinco linhas de soja com $10 \mathrm{~m}$ de 

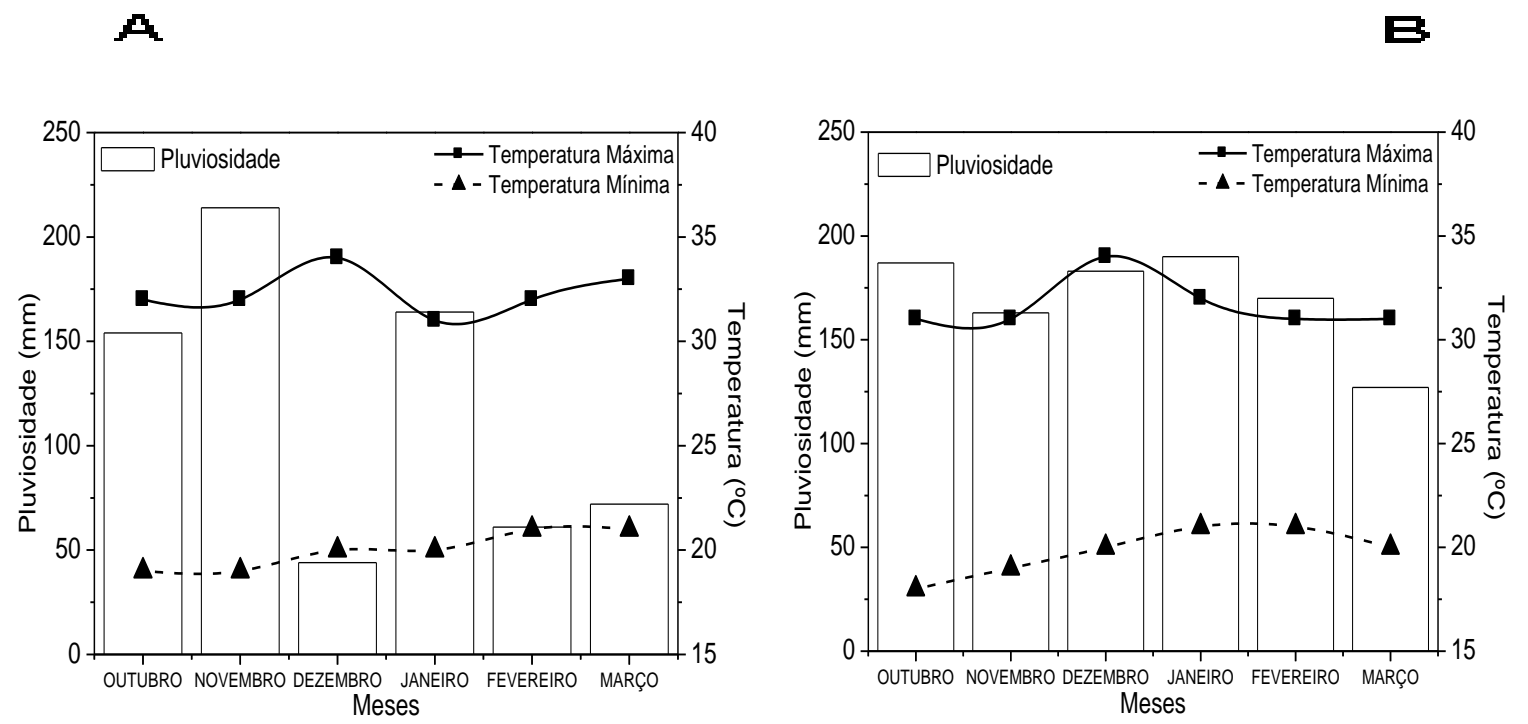

Figura 1. Pluviosidade e temperatura máxima e mínima da safra 2008/2009 (A) e série histórica de 31 anos (B) da região de Naviraí-MS. Fonte: EMBRAPA - Dourados-MS.

comprimento, espaçadas entre si de $0,45 \mathrm{~m}$. Por ocasião da colheita considerou-se as três linhas centrais, descontando-se a bordadura, de maneira que a área útil de cada parcela correspondeu a $10,8 \mathrm{~m}^{2}$.

As amostras de solos foram coletadas nas profundidades de $0-20 \mathrm{~cm}, 40-60 \mathrm{~cm}$, $60-80 \mathrm{~cm}$ e $80-100 \mathrm{~cm}$, com uso de trado pedológico sendo realizada uma amostragem por classe textural de solo (LVe-2, LVe-3 e LVe-4) para efeito de classificação pedológica.

Posteriormente, as referidas amostras foram encaminhadas ao Laboratório de Solos para realização das análises pedológicas, cujos resultados foram utilizados para confirmação da classificação pedológica dos solos das áreas experimentais, de acordo com identificação de Prado (2008) (Tabela 1).

Para o levantamento da fertilidade de cada área experimental (classe textural) efetuou-se amostragem de solo, conforme metodologia proposta por Embrapa (2008), nas profundidades 0 a $10 \mathrm{~cm}, 10$ a $20 \mathrm{~cm} \mathrm{e}$ 20 a $40 \mathrm{~cm}$, com o uso de trado tipo sonda. Em seguida as amostras foram submetidas as análises de fertilidade de acordo com metodologia proposta por Raij (1991) (Tabelas 2 e 3 ).

Em todas as classes texturais dos solos as cultivares de soja foram semeadas no dia 15 de novembro de 2008 em sistema plantio direto sobre a resteva de milho segunda safra. As épocas de colheita foram definidas pelo próprio grupo de maturação de cada cultivar, efetuando-se a colheita no período entre o mês de março (precoces) e início do mês de abril (cultivares médios) de 2009. A adubação de base foi realizada simultaneamente com a semeadura utilizando o fertilizante 00-18-18 na dose de $333 \mathrm{~kg} \mathrm{ha}^{-1}$, dimensionados através dos resultados das análises fertilidade (Tabela 3) e recomendação da Embrapa (2008).

Quando as plantas atingiram o estádio fenológico vegetativo $\mathrm{V}_{1}$, avaliaram-se os estandes iniciais das linhas de cada parcela, efetuando-se, quando necessário, o desbaste de plantas, estabelecendo-se assim, o estande inicial de cada cultivar de acordo com as recomendações de populações por parte dos obtentores de cada cultivar.

Previamente à semeadura das cultivares, as sementes foram tratadas com fungicida (Carbendazin + Thiran), inseticida 
(fipronil) e solução contendo sais de cobalto e molibdênio de acordo com o proposto por Embrapa (2008). Como última operação antes da semeadura, as sementes foram inoculadas com inoculante líquido. A semeadura totalmente mecanizada ocorreu pela utilização de semeadora-adubadora contendo cinco unidades de distribuição de sementes espaçadas entre si de $0,45 \mathrm{~m}$. O controle de pragas e plantas daninhas foi realizado de acordo com as recomendações da Embrapa (2008), bem como o controle das principais doenças, realizado de forma preventiva. Uma vez atingido o ponto de maturação final $\left(\mathrm{R}_{8}\right)$ definido por Fehr \& Caviness (1977) foi efetuada a colheita manual das parcelas de soja, por meio de podões com o corte basal da haste principal. As plantas colhidas na área útil de cada parcela foram enfeixadas e transportadas para a trilha estacionária instalada nas dependências da Cooperativa Agrícola Sul Matogrossense (COPASUL), Naviraí-MS. Os grãos trilhados foram previamente limpos, pesados e embalados.
A amostragem das folhas foi realizada no florescimento (R2) definido por Fehr \& Caviness (1977). Foram coletadas 30 trifólios com pecíolo da terceira folha a partir da extremidade da haste principal Malavolta (2006). O material foi seco à sombra até atingir peso constante e enviado ao laboratório para determinação dos teores de macro e micronutrientes segundo metodologia descrita por Malavolta et al., (1997). Previamente à colheita, dez plantas por parcela foram aleatoriamente coletadas, de acordo com metodologia descrita por Heiffig (2002), para contagem do número de total de vagens formadas por plantas e grãos por vagem. Determinou-se, através da coleta ao acaso e pesagem de oito amostras de 100 grãos, todos corrigido a $13 \%$ de umidade de acordo com a metodologia descrita em Regras para análise de sementes Brasil (2009).

A produtividade média foi obtida após pesagem dos grãos provenientes de cada parcela, corrigindo a umidade para $13 \%$, sendo os valores expressos em $\mathrm{kg} \mathrm{ha}^{-1}$.

Tabela 1. Classificação pedológica dos solos das áreas experimentais com base nos resultados das respectivas análises químicas e físicas pedológicas.

\begin{tabular}{|c|c|c|c|c|c|c|c|c|c|c|c|c|c|c|c|}
\hline \multirow{3}{*}{ Solo } & \multirow{2}{*}{ Prof. } & \multicolumn{14}{|c|}{ Químico } \\
\hline & & $\mathbf{p} \mathbf{H}^{(\mathbf{1})}$ & $\mathrm{H}+\mathrm{Al}$ & Al & $\mathbf{C a}$ & Mg & $\mathbf{K}$ & $\mathbf{N a}$ & $\mathbf{P}^{(1)}$ & $\mathrm{C}$ & SB & CTC & $\mathbf{V}$ & RC & Argila \\
\hline & \multicolumn{4}{|l|}{$\mathrm{cm}$} & \multicolumn{4}{|c|}{$\mathrm{cmol}_{\mathbf{c}} \mathbf{d m}^{-3}$} & $\begin{array}{c}\mathbf{m g} \\
\mathbf{d m}^{-3}\end{array}$ & g.kg ${ }^{-1}$ & cmol & & $\%$ & & g. $\mathbf{K g}^{-1}$ \\
\hline \multirow{5}{*}{ LVe-2 } & $00-20$ & 6,4 & 1,2 & 0,0 & 1,9 & 1,1 & 0,2 & 0,0 & 11,0 & 12,0 & 3,2 & 4,4 & 72,9 & 15,5 & 206,0 \\
\hline & $20-40$ & 6,0 & 1,4 & 0,0 & 1,3 & 0,8 & 0,3 & 0,0 & 4,0 & 10,0 & 2,4 & 3,8 & 63,2 & 11,0 & 218,0 \\
\hline & $40-60$ & 5,5 & 1,8 & 0,0 & 1,0 & 0,6 & 0,3 & 0,0 & 2,0 & 8,0 & 1,9 & 3,7 & 51,1 & 7,0 & 270,0 \\
\hline & $60-80$ & 5,5 & 1,6 & 0,0 & 1,2 & 0,6 & 0,2 & 0,0 & 6,0 & 6,0 & 2,0 & 3,6 & 55,6 & 6,4 & 315,0 \\
\hline & $80-100$ & 5,6 & 1,6 & 0,0 & 1,0 & 0,6 & 0,1 & 0,0 & 5,0 & 4,0 & 1,8 & 3,4 & 52,2 & 5,4 & 323,0 \\
\hline \multirow{5}{*}{ LVe-3 } & $00-20$ & 5,5 & 2,8 & 0,0 & 3,3 & 1,0 & 0,3 & 0,1 & 6,0 & 17,0 & 4,7 & 7,5 & 62,5 & 10,8 & 432,0 \\
\hline & $20-40$ & 5,7 & 2,0 & 0,0 & 3,0 & 0,8 & 0,1 & 0,1 & 3,0 & 13,3 & 3,9 & 5,9 & 66,3 & 8,7 & 450,0 \\
\hline & $40-60$ & 6,1 & 1,6 & 0,0 & 2,9 & 0,7 & 0,1 & 0,1 & 7,0 & 10,0 & 3,7 & 5,3 & 69,6 & 7,4 & 496.0 \\
\hline & $60-80$ & 6,2 & 1,6 & 0,0 & 3,2 & 0,6 & 0,1 & 0,1 & 3,0 & 7,0 & 3,9 & 5,5 & 70,8 & 8,2 & 471,0 \\
\hline & $80-100$ & 6,4 & 1,4 & 0,0 & 3,6 & 0,6 & 0,1 & 0,1 & 2,0 & 4,0 & 4,3 & 5,7 & 75,4 & 8,8 & 484,0 \\
\hline \multirow{5}{*}{ LVe-4 } & $00-20$ & 5,9 & 2,0 & 0,0 & 4,2 & 1,4 & 0,3 & 0,1 & 7,0 & 18,0 & 5,9 & 7,9 & 74,8 & 11,9 & 497,0 \\
\hline & $20-40$ & 5,8 & 2,2 & 0,0 & 2,3 & 0,9 & 0,3 & 0,0 & 2,0 & 14,0 & 3,5 & 5,7 & 61,5 & 6,8 & 521,0 \\
\hline & $40-60$ & 5,9 & 2,0 & 0,0 & 2,2 & 0,8 & 0,1 & 0,1 & 3,0 & 10,0 & 3,2 & 5,2 & 61,5 & 5,7 & 565,0 \\
\hline & $60-80$ & 6,1 & 1,6 & 0,0 & 2,4 & 0,9 & 0,1 & 0,1 & 2,0 & 8,0 & 3,5 & 5,1 & 68,4 & 5,8 & 602,0 \\
\hline & $80-100$ & 6,2 & 1,6 & 0,0 & 2,1 & 0,9 & 0,1 & 0,1 & 2,0 & 5,0 & 3,1 & 4,7 & 66,2 & 5,1 & 620,0 \\
\hline
\end{tabular}

Extratores: pH (Relação 1:2,5); $\mathrm{H}+\mathrm{Al}$ (Acetato de cálcio $0,5 \mathrm{~mol} \mathrm{~L}^{-1}, \mathrm{pH} 7,0$ ); $\mathrm{Ca}, \mathrm{Mg}, \mathrm{K}, \mathrm{e} \mathrm{Na}$ (Acetato de amônio pH 7,0); P (Resina); C (1,72 x teor de carbono determinado pelo método da oxidação com dicromato de potássio em meio ácido); Argila (Método Pipeta). 
Tabela 2. Resultados da análise química dos solos das áreas experimentais - componentes de acidez, matéria orgânica e de fertilidade em macronutrientes.

\begin{tabular}{|c|c|c|c|c|c|c|c|c|c|c|c|c|c|}
\hline \multirow{3}{*}{ Solo } & \multirow{3}{*}{$\begin{array}{c}\text { Prof. } \\
\text { cm }\end{array}$} & \multicolumn{12}{|c|}{ Macronutrientes } \\
\hline & & $\mathbf{p H}^{(\mathbf{1})}$ & $\mathrm{H}+\mathrm{Al}$ & $\mathbf{A l}^{3+}$ & $\mathrm{Ca}^{2+}$ & $\mathrm{Mg}^{2+}$ & $\mathbf{K}$ & $\mathbf{P}^{(1)}$ & S & MO & SB & CTC & V \\
\hline & & & \multicolumn{3}{|c|}{$\mathrm{cmol}_{\mathrm{c}} \mathrm{dm}^{-3}$} & \multicolumn{4}{|c|}{$\mathrm{mg} \mathrm{dm}^{-3}$} & g.kg- & $\mathrm{cmol}_{\mathrm{c}} \mathrm{dm}^{-3}$ & & $\%$ \\
\hline \multirow{3}{*}{ LVe-2 } & $(00-10)$ & 6,8 & 1,4 & 0,0 & 2,6 & 1,2 & 0,2 & 28,0 & 7,1 & 20,8 & 4,0 & 5,3 & 74,2 \\
\hline & $(10-20)$ & 5,8 & 2,1 & 0,0 & 1,8 & 0,8 & 0,2 & 21,8 & 7,8 & 15,3 & 2,8 & 4,8 & 57,4 \\
\hline & $(20-40)$ & 5,7 & 2,3 & 0,0 & 1,6 & 0,6 & 0,1 & 11,8 & 5,7 & 9,3 & 2,3 & 4,6 & 49,6 \\
\hline \multirow{3}{*}{ LVe-3 } & $(00-10)$ & 5,7 & 3,2 & 0,0 & 3,2 & 1,0 & 0,3 & 17,8 & 5,9 & 28,5 & 4,5 & 7,7 & 58,9 \\
\hline & $(10-20)$ & 5,4 & 3,8 & 0,0 & 2,5 & 0,8 & 0,2 & 6,0 & 4,7 & 22,8 & 3,4 & 7,2 & 47,5 \\
\hline & $(20-40)$ & 5,5 & 3,7 & 0,0 & 1,8 & 0,6 & 0,1 & 5,8 & 11,8 & 13,8 & 2,6 & 6,2 & 41,3 \\
\hline \multirow{3}{*}{ LVe-4 } & $\begin{array}{l}(00-10) \\
\end{array}$ & 6,3 & 2,0 & 0,0 & 4,5 & 1,4 & 0,3 & 23,5 & 9,8 & 28,0 & 6,2 & 8,1 & 75,2 \\
\hline & $(10-20)$ & 5,7 & 2,8 & 0,0 & 3,2 & 0,9 & 0,1 & 8,3 & 11,8 & 21,5 & 4,2 & 7,0 & 59,5 \\
\hline & $(20-40)$ & 5,9 & 2,5 & 0,0 & 2,6 & 0,8 & 0,1 & 5,5 & 5,8 & 12,5 & 3,5 & 6,0 & 58,7 \\
\hline
\end{tabular}

Tabela 3. Resultados da análise química dos solos das áreas experimentais - micronutrientes.

\begin{tabular}{ccccccc}
\hline \multirow{2}{*}{ Solo } & \multirow{2}{*}{$\begin{array}{c}\text { Prof. } \\
\mathbf{c m}\end{array}$} & \multicolumn{7}{c}{ Micronutrientes } \\
\cline { 3 - 7 } & & $\mathbf{B}$ & $\mathbf{F e}$ & $\mathbf{M n}$ & $\mathbf{C u}$ & $\mathbf{Z n}$ \\
\cline { 3 - 7 } & $(00-10)$ & & & $\mathrm{mg} \mathrm{dm}^{-3}$ & & \\
\multirow{2}{*}{ LVe-2 } & $(10-20)$ & 0,2 & 90,5 & 22,0 & 1,4 & 8,3 \\
& $(20-40)$ & 0,2 & 89,7 & 17,1 & 1,1 & 3,4 \\
& $(00-10)$ & 0,2 & 82,8 & 9,3 & 1,3 & 1,0 \\
\hline \multirow{2}{*}{ LVe-3 } & $(10-20)$ & 0,2 & 78,5 & 28,8 & 6,2 & 10,8 \\
& $(20-40)$ & 0,2 & 82,2 & 1,2 & 2,9 & 2,8 \\
& $(00-10)$ & 0,2 & 75,1 & 32,4 & 3,3 & 1,0 \\
\hline \multirow{2}{*}{ LVe-4 } & $(10-20)$ & 0,2 & 78,3 & 21,7 & 3,3 & 2,9 \\
& $(20-40)$ & 0,2 & 94,2 & 15,5 & 4,5 & 1,8 \\
\hline
\end{tabular}

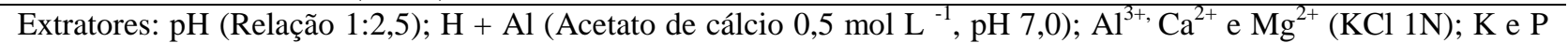
(Melich-1, relação 1:10); S (Fosfato monocálcico); MO (1,72 x teor de carbono determinado pelo método da oxidação com dicromato de potássio em meio ácido).

Extratores: B (Água quente); Fe, Mn, Cu e Zn (Melich-1, relação 1:10).

As avaliações agronômicas foram realizadas de maneira independente para cada classe de solo (LVe-2, LVe-3 e LVe-4), cujos resultados foram submetidos a análise de variância (ANOVA, <0,05) e ao teste de comparação de médias Tukey $(<0,05)$ pelo programa estatístico SISVAR 5.0.

\section{RESULTADOS E DISCUSSÃO}

Verificou-se que os teores foliares de $\mathrm{P}$, em todas as cultivares avaliadas, estão abaixo da faixa de suficiência (Tabela 4), apesar dos resultados das análises químicas apresentarem nível de $\mathrm{P}$ classificado como bom (EMBRAPA, 2008). Segundo
Malavolta (2006) os baixos teores foliares de $\mathrm{P}$ pode ser explicado pelo alto teor foliar de Ca.

Com relação ao $\mathrm{K}$, apenas as cultivares BRS CharruaRR e BRS 245RR apresentaram teores foliares dentro da faixa de suficiência Embrapa (2008), enquanto os demais cultivares apresentaram valores abaixo do limite inferior Embrapa (2008). Tais resultados podem ser explicados pela competição catiônica, onde o aumento na absorção de um cátion $\left(\mathrm{Ca}^{2+}\right)$ provoca o decréscimo na absorção de outro $\left(\mathrm{K}^{+}\right)$ Throeh \& Thomposon (2007).

Todas as cultivares apresentaram teores foliares de $\mathrm{S}$ abaixo dos respectivos 
valores correspondentes à faixa de suficiência de cada elemento (EMBRAPA, 2008). Estes baixos teores foliares de $S$ estão relacionados com os baixos teores foliares de $\mathrm{P}$, pois de acordo com Malavolta (2006), o teor de $\mathrm{P}$ na folha está relacionado com o de S e vice-versa. Richart et al., (2006) também verificaram, em trabalho realizado a campo no estado do Paraná, que o teor de $\mathrm{S}$ no tecido foliar aumentou com a adubação fosfatada.

Os resultados dos teores foliares do B estão suficientes, embora os resultados de análise química do solo apresentarem níveis classificados como baixos por Embrapa (2008). A suficiência foliar do B pode ser explicada pelos baixos teores foliares de $\mathrm{P}$ nas plantas, pois de acordo com Malavolta (2006), plantas deficientes em $\mathrm{P}$ possuem maior concentração de $B$.

Já em relação aos teores de $\mathrm{N}, \mathrm{Ca}$, $\mathrm{Mg}, \mathrm{Fe}, \mathrm{Mn}, \mathrm{Cu}$ e $\mathrm{Zn}$, os resultados dos teores foliares mostraram-se suficientes ou altos, de acordo com classificação proposta por Embrapa (2008). Estes resultados indicam que nesta classe textural (LVe-2), o alto nível de fertilidade do solo refletiu nos teores foliares da planta (Tabela 4).

Já a cultivar CD 219RR foi a que absorveu maiores quantidades de $\mathrm{N}, \mathrm{S}, \mathrm{Fe}$, $\mathrm{Cu}$ e B, enquanto a cultivar CD 208 absorveu as menores quantidades de $\mathrm{N}, \mathrm{P}$ e
$\mathrm{B}$, ilustrando as diferenças entre genótipos quanto à capacidade e à eficiência em absorver nutrientes de uma mesma classe de solo, ou de um mesmo ambiente de produção.

Quanto ao LVe-3, para todas as cultivares, exceto a CD 219RR, verificou-se teores foliares de $\mathrm{N}$ abaixo do limite inferior da faixa de suficiência (Embrapa 2008). Segundo Hungria (1997) as plantas de soja nas condições brasileiras de cultivo chegam consumir até $97 \%$ da necessidade de $\mathrm{N}$ através da fixação biológica. Desta forma este nutriente não seria limitante para a soja e os teores foliares baixos podem estar relacionados ao maior teor de argila presente no solo LVe-3, comparado ao Lve-2 Santos (2008). Os baixos teores de $\mathrm{P}$ nos cultivares CD 202 e CD 208 podem estar relacionados aos altos teores foliares do $\mathrm{Ca}$, pois de acordo com Malavolta (2006), concentrações não excessivas de $\mathrm{Ca}$ elevam os teores foliares de $\mathrm{P}$, enquanto o excesso reduz, podendo este efeito estar relacionado com o $\mathrm{pH}$ ou a formação de fosfato de cálcio insolúvel.

Assim como na classe textural LVe2, os baixos teores de $\mathrm{K}$ na grande maioria dos cultivares conduzido nesta classe textural (LVe-3) podem estar associados a competição entre cátions Throeh \& Thompson (2007).

Tabela 4. Resultados observados para os teores foliares de macro e micronutrientes das cultivares de soja instaladas no Latossolo Vermelho Eutrófico textura média (LVe2).

\begin{tabular}{lccccccccccc}
\hline \multirow{3}{*}{ Cultivares } & \multicolumn{4}{c}{ Macronutriente } & \multicolumn{4}{c}{ Micronutriente } \\
\cline { 2 - 12 } & $\mathbf{N}$ & $\mathbf{4}$ & $\mathbf{3}$ & $\mathbf{C a}$ & $\mathbf{M g}$ & $\mathbf{S}$ & $\mathbf{F e}$ & $\mathbf{M n}$ & $\mathbf{C u}$ & $\mathbf{Z n}$ & $\mathbf{B}$ \\
\hline CD 202 & 39,37 & 1,87 & 15,77 & 23,40 & 5,40 & 1,57 & 156,33 & 314,33 & 10,33 & 60,67 & 45,23 \\
CD 208 & 38,10 & 1,60 & 15,53 & 19,53 & 5,30 & 1,63 & 155,33 & 291,33 & 9,00 & 44,00 & 34,87 \\
CD 214RR & 42,67 & 1,80 & 13,40 & 20,57 & 5,73 & 1,73 & 171,67 & 259,33 & 8,33 & 43,33 & 35,93 \\
BRS 239 & 43,97 & 1,80 & 15,13 & 22,10 & 5,27 & 1,77 & 177,33 & 328,33 & 8,33 & 52,67 & 41,23 \\
BRS CharruaRR & 42,23 & 1,93 & 19,33 & 18,97 & 5,43 & 1,67 & 151,00 & 285,00 & 9,33 & 41,67 & 42,43 \\
BRS 245RR & 43,47 & 2,17 & 18,70 & 17,73 & 5,00 & 1,67 & 168,00 & 183,33 & 9,67 & 38,00 & 43,67 \\
CD 219RR & 46,73 & 2,10 & 15,47 & 21,13 & 4,73 & 1,77 & 182,67 & 215,33 & 11,00 & 49,33 & 47,37 \\
Monsoy 8001 & 41,17 & 1,70 & 16,67 & 22,37 & 5,03 & 1,67 & 170,67 & 236,67 & 8,67 & 40,33 & 42,93 \\
\hline
\end{tabular}


Da mesma forma, no ambiente LVe3 (Tabela 5), a cultivar CD 219RR foi a que mais absorveu $\mathrm{N}, \mathrm{P}, \mathrm{Cu}$ e $\mathrm{Zn}$, enquanto as cultivares CD 208 e BRS CharruaRR novamente mostraram-se menos eficientes na absorção de nutrientes, principalmente $\mathrm{N}$, $\mathrm{P}, \mathrm{S}$ e B. Quanto ao ambiente LVe-4, nota-se que em relação ao $\mathrm{N}$, as cultivares de ciclo precoce e semiprecoce apresentaram teores foliares abaixo do limite inferior da faixa de suficiência Embrapa (2008) (Tabela 6). No entanto, estas cultivares apresentaram elevada produtividade, podendo inferir que ocorreu grande absorção de $\mathrm{N}$ neste ambiente, sendo este nutriente consumido pelas plantas para a formação de grãos. Segundo Fageria et al., (1999), a relação inversa do teor foliar de $\mathrm{N}$ e produtividade pode indicar efeito de diluição ou mesmo que plantas mais produtivas são mais eficientes na utilização desse nutriente. Para o K, as cultivares CD 202, CD 214RR, BRS 239 e CD 219RR apresentaram baixos teores desse nutriente (Embrapa 2008) podendo ter ocorrido a absorção competitivas entre cátions ( $\mathrm{Ca}, \mathrm{Mg}, \mathrm{Fe}, \mathrm{Mn}$ e $\mathrm{Zn}$ ), segundo Malavolta (2006).

Os resultados da análise química dos solos revelaram que o solo mais equilibrado é o LVe-4, classificado como bom por
Embrapa (2008). Neste ambiente, a cultivar CD 219RR se destacou pelas maiores quantidades absorvidas de N, S, Cu, Zn e B. Dentre as que absorveram menores quantidades de macro e micronutrientes destacam-se CD 214RR (, $\mathrm{Cu}$ e $\mathrm{Zn}$ ), BRS 239 (N, K e B) e BRS 245RR (Mg, Fe e Zn).

Para o componente de produção número de vagens por planta, no ambiente LVe-2, maior valor foi encontrado para a cultivar CD 214 RR, significativamente superior aos valores observados para as cultivares CD 202, BRS 239, BRS CharruaRR, CD 219RR e Monsoy 8001. Com relação ao número de grãos por vagens, a cultivar CD 208 foi significativamente superior à cultivar BRS 245RR (Tabela 7). Já em relação ao peso de mil grãos, verificou-se diferença estatística significativa apenas entre os cultivares CD 202 e Monsoy 8001 (Tabela 7). Quanto à produtividade agrícola de grãos, a cultivar CD 202 mostrou-se mais produtiva, significativamente superior às produtividades agrícolas observadas para as cultivares BRS 245RR, CD 219RR e Monsoy 8001, alcançando uma diferença superior à $1.200 \mathrm{~kg} \mathrm{ha}^{-1}$ em relação a BRS 245RR e Monsoy 8001 (Tabela 7).

Tabela 5. Resultados observados para os teores foliares de macro e micronutrientes das cultivares de soja instaladas no Latossolo Vermelho Eutrófico textura argilosa (LVe-3).

\begin{tabular}{|c|c|c|c|c|c|c|c|c|c|c|c|}
\hline \multirow{3}{*}{ Cultivares } & \multicolumn{6}{|c|}{ Macronutriente } & \multicolumn{5}{|c|}{ Micronutriente } \\
\hline & $\mathbf{N}$ & $\mathbf{P}$ & $\mathbf{K}$ & $\mathbf{C a}$ & $\mathbf{M g}$ & $\mathbf{S}$ & $\mathbf{F e}$ & Mn & $\mathbf{C u}$ & $\mathbf{Z n}$ & B \\
\hline & \multicolumn{6}{|c|}{ g. $\mathrm{Kg}^{-1}$} & \multicolumn{5}{|c|}{$\mathrm{mg} \cdot \mathrm{Kg}^{-1}$} \\
\hline CD 202 & 31,97 & 2,23 & 12,37 & 25,60 & 3,87 & 2,70 & 176,33 & 219,33 & 7,67 & 62,33 & 67,00 \\
\hline CD 208 & 30,83 & 2,20 & 16,17 & 23,90 & 2,50 & 2,23 & 236,67 & 202,67 & 8,67 & 57,00 & 53,40 \\
\hline CD 214RR & 31,60 & 2,63 & 14,17 & 20,43 & 3,40 & 2,70 & 211,00 & 192,00 & 7,67 & 46,67 & 57,07 \\
\hline BRS 239 & 32,27 & 2,40 & 12,13 & 23,50 & 3,47 & 2,53 & 205,67 & 201,33 & 7,67 & 66,67 & 49,10 \\
\hline BRS CharruaRR & 34,60 & 2,77 & 18,33 & 17,87 & 2,13 & 2,87 & 200,00 & 164,00 & 9,33 & 46,00 & 64,10 \\
\hline BRS 245RR & 33,20 & 2,77 & 16,27 & 19,17 & 3,40 & 2,50 & 187,67 & 208,33 & 8,67 & 49,33 & 66,83 \\
\hline CD 219RR & 37,23 & 3,03 & 17,53 & 18,03 & 3,23 & 2,67 & 229,67 & 193,67 & 11,67 & 68,67 & 66,47 \\
\hline Monsoy 8001 & 36,20 & 3,03 & 14,23 & 18,47 & 3,37 & 2,70 & 232,67 & 218,33 & 11,33 & 67,33 & 59,53 \\
\hline
\end{tabular}


Tabela 6. Resultados observados para os teores foliares de macro e micronutrientes das cultivares instaladas no Latossolo Vermelho Eutrófico textura muito argilosa (LVe4).

\begin{tabular}{|c|c|c|c|c|c|c|c|c|c|c|c|}
\hline \multirow{3}{*}{ Cultivares } & \multicolumn{6}{|c|}{ Macronutriente } & \multicolumn{5}{|c|}{ Micronutriente } \\
\hline & $\mathbf{N}$ & $\mathbf{P}$ & $\mathbf{K}$ & $\mathbf{C a}$ & Mg & $\mathbf{S}$ & $\mathbf{F e}$ & Mn & $\mathbf{C u}$ & $\mathbf{Z n}$ & B \\
\hline & \multicolumn{6}{|c|}{ g. $\mathrm{Kg}^{-1}$} & \multicolumn{5}{|c|}{$\mathrm{mg} \cdot \mathrm{Kg}^{-1}$} \\
\hline CD 202 & 35,07 & 2,40 & 15,43 & 23,57 & 3,13 & 2,50 & 246,00 & 187,67 & 6,67 & 47,00 & 53,97 \\
\hline CD 208 & 31,30 & 2,07 & 18,20 & 16,67 & 2,90 & 2,50 & 285,00 & 238,00 & 7,33 & 34,67 & 46,83 \\
\hline CD 214RR & 32,17 & 2,17 & 15,80 & 18,07 & 2,93 & 2,33 & 222,33 & 157,33 & 6,67 & 26,33 & 43,97 \\
\hline BRS 239 & 31,03 & 2,43 & 15,43 & 22,37 & 3,50 & 2,53 & 218,00 & 155,67 & 7,00 & 34,67 & 38,27 \\
\hline BRS CharruaRR & 36,33 & 2,60 & 19,10 & 18,67 & 2,40 & 2,63 & 208,67 & 169,33 & 8,00 & 35,33 & 45,20 \\
\hline BRS 245RR & 37,00 & 2,33 & 19,13 & 16,57 & 2,20 & 2,43 & 202,33 & 118,33 & 7,00 & 26,33 & 52,80 \\
\hline CD 219RR & 39,67 & 2,60 & 17,10 & 12,83 & 2,40 & 2,97 & 270,67 & 116,67 & 10,33 & 50,33 & 56,23 \\
\hline Monsoy 8001 & 38,73 & 2,90 & 20,10 & 16,80 & 2,33 & 2,90 & 259,67 & 157,67 & 9,00 & 43,67 & 49,10 \\
\hline
\end{tabular}

Tabela 7. Resultados dos componentes de produção das cultivares instaladas no LVe-2. As letras apresentam as análises estatísticas pelo teste de comparação de médias Tukey $(\mathrm{p}<0,05)$, onde as letras maiúsculas identificam diferenças entre as cultivares.

\begin{tabular}{lcccc}
\hline \multirow{2}{*}{ Cultivares } & Vagens/Planta & Grãos/Vagem & Peso Mil Grãos & Produtividade \\
\cline { 2 - 5 } & & & $\mathrm{g}$ & $\mathrm{Kg}^{\mathrm{o}}$ \\
\cline { 2 - 5 } CD 202 & & $2,02^{\mathrm{ab}}$ & $145,42^{\mathrm{a}}$ & $3.419,60^{\mathrm{a}}$ \\
CD 208 & $77,30^{\mathrm{b}}$ & $2,39^{\mathrm{a}}$ & $128,08^{\mathrm{ab}}$ & $3.122,06^{\mathrm{ab}}$ \\
CD 214 & $87,70^{\mathrm{ab}}$ & $2,22^{\mathrm{ab}}$ & $113,99^{\mathrm{ab}}$ & $2.656,77^{\mathrm{b}}$ \\
BRS 239 & $141,77^{\mathrm{a}}$ & $2,29^{\mathrm{ab}}$ & $139,43^{\mathrm{ab}}$ & $2.658,63^{\mathrm{b}}$ \\
BRS Charrua & $72,03^{\mathrm{b}}$ & $2,09^{\mathrm{ab}}$ & $125,18^{\mathrm{ab}}$ & $2.811,30^{\mathrm{b}}$ \\
BRS 245 & $77,83^{\mathrm{b}}$ & $1,92^{\mathrm{b}}$ & $122,55^{\mathrm{ab}}$ & $2.057,71^{\mathrm{c}}$ \\
CD 219 RR & $96,20^{\mathrm{ab}}$ & $2,18^{\mathrm{ab}}$ & $120,28^{\mathrm{ab}}$ & $2.364,39^{\mathrm{bc}}$ \\
Monsoy 8001 & $79,67^{\mathrm{b}}$ & $2,16^{\mathrm{ab}}$ & $97,09^{\mathrm{b}}$ & $2.148,45^{\mathrm{c}}$ \\
\hline Média geral & $84,37^{\mathrm{b}}$ & 2,15 & 124,00 & $2.654,86$ \\
C.V. \% & 89,60 & 6,57 & 12,77 & 12,25 \\
DMS & 21,16 & 0,40 & 45,60 & 937,67 \\
\hline
\end{tabular}

Para a classe textural LVe-2 houve uma relação direta entre produtividade e peso de mil grãos, pois a cultivar mais produtiva foi também a que apresentou o maior peso de mil grãos, CD 202, indicando assim uma relação direta entre peso de mil grãos e produtividade. Diferentemente do que foi observado por Motta et al., (2000), onde as cultivares mais produtivas não apresentaram os maiores valores de peso de mil grãos.

Em relação ao $\mathrm{LVe}-3$, a análise de variância apresentou valores significativos apenas para o parâmetro número de vagens por planta. A cultivar CD 214RR foi estatisticamente superior às cultivares BRS CharruaRR, BRS 245RR, CD 219RR e Monsoy 8001, produzindo 56 vagens por planta a mais, comparada a cultivar CD 219RR. Embora sem diferenças significativas entre cultivares para $o$ parâmetro produtividade agrícola de grãos, a cultivar CD 214RR foi aproximadamente $950 \mathrm{~kg} \mathrm{ha}^{-1}$ mais produtivo que a cultivar CD 219RR (Tabela 8). De acordo com Junior \& Costa (2002), é relativa a importância de cada componente de produção para as diferentes cultivares de soja.

Quanto ao LVe-4, a análise de variância revelou valores significativos apenas para os parâmetros número de grãos por vagem e produtividade agrícola de grãos (Tabela 9). A cultivar CD 208 apresentou, em média, 2,56 grãos por vagem, valor este significativamente superior aos valores 
Tabela 8. Resultados dos componentes de produção das cultivares instaladas no LVe-3. As letras apresentam as análises estatísticas pelo teste de comparação de médias Tukey $(\mathrm{p}<0,05)$, onde as letras maiúsculas identificam diferenças entre as cultivares.

\begin{tabular}{|c|c|c|c|c|}
\hline \multirow{2}{*}{ Cultivares } & Vagens/Planta & Grãos/Vagem & Peso Mil Grãos & Produtividade \\
\hline & \multicolumn{2}{|c|}{$\mathrm{N}^{\mathrm{o}}$} & $\mathrm{g}$ & Kg.ha'-1 \\
\hline CD 202 & $68,10^{\mathrm{NS}}$ & $2,04^{b}$ & $160,64^{\mathrm{NS}}$ & $3852,92^{\mathrm{a}}$ \\
\hline CD 208 & $67,20^{\mathrm{NS}}$ & $2,58^{\mathrm{a}}$ & $135,47^{\mathrm{NS}}$ & $3569,89^{a}$ \\
\hline CD $214 R R$ & $79,13^{\mathrm{NS}}$ & $1,98^{\mathrm{b}}$ & $126,98^{\mathrm{NS}}$ & $2964,69^{b}$ \\
\hline BRS 239 & $62,73^{\mathrm{NS}}$ & $2,32^{\mathrm{ab}}$ & $142,32^{\mathrm{NS}}$ & $3400,31^{\mathrm{ab}}$ \\
\hline BRS Charrua RR & $56,17^{\mathrm{NS}}$ & $2,30^{\mathrm{ab}}$ & $116,70^{\mathrm{NS}}$ & $2775,77^{\mathrm{c}}$ \\
\hline BRS 245 RR & $58,80^{\mathrm{NS}}$ & $2,14^{\mathrm{ab}}$ & $116,92^{\mathrm{NS}}$ & $2989,75^{\mathrm{b}}$ \\
\hline CD 219 RR & $57,43^{\mathrm{NS}}$ & $2,32^{\mathrm{ab}}$ & $159,78^{\mathrm{NS}}$ & $2607,34^{\mathrm{c}}$ \\
\hline Monsoy 8001 & $64,00^{\mathrm{NS}}$ & $2,10^{\mathrm{b}}$ & $98,31^{\mathrm{NS}}$ & $2762,24^{\mathrm{c}}$ \\
\hline Média geral & 64,19 & 2,22 & 132,13 & $3.115,36$ \\
\hline C.V.\% & 15,06 & 7,41 & 22,59 & 6,32 \\
\hline DMS & 27,87 & 0,47 & 86,05 & 567,33 \\
\hline
\end{tabular}

Tabela 9. Resultados dos componentes de produção das cultivares instaladas no LVe-4. As letras apresentam as análises estatísticas pelo teste de comparação de médias Tukey $(\mathrm{p}<0,05)$, onde as letras maiúsculas identificam diferenças entre as cultivares.

\begin{tabular}{|c|c|c|c|c|}
\hline \multirow{2}{*}{ Cultivares } & Vagens/Planta & Grãos/Vagem & Peso Mil Grãos & Produtividade \\
\hline & \multicolumn{2}{|c|}{$\mathrm{N}^{\mathrm{o}}$} & $\mathrm{g}$ & Kg.ha $^{-1}$ \\
\hline CD 202 & $94,23^{\mathrm{ab}}$ & $2,24^{\mathrm{NS}}$ & $153,44^{\mathrm{NS}}$ & $2951,24^{\mathrm{NS}}$ \\
\hline CD 208 & $87,13^{\mathrm{ab}}$ & $2,48^{\mathrm{NS}}$ & $129,68^{\mathrm{NS}}$ & $3477,67^{\mathrm{NS}}$ \\
\hline CD $214 R R$ & $118,43^{\mathrm{a}}$ & $2,21^{\mathrm{NS}}$ & $112,97^{\mathrm{NS}}$ & $3533,04^{\mathrm{NS}}$ \\
\hline BRS 239 & $88,13^{\mathrm{ab}}$ & $2,11^{\mathrm{NS}}$ & $129,61^{\mathrm{NS}}$ & $3342,07^{\mathrm{NS}}$ \\
\hline BRS Charrua RR & $78,90^{\mathrm{b}}$ & $2,19^{\mathrm{NS}}$ & $151,83^{\mathrm{NS}}$ & $2773,19^{\mathrm{NS}}$ \\
\hline BRS 245 RR & $71,87^{\mathrm{b}}$ & $2,18^{\mathrm{NS}}$ & $126,30^{\mathrm{NS}}$ & $3086,61^{\mathrm{NS}}$ \\
\hline CD $219 R R$ & $61,77^{\mathrm{b}}$ & $2,43^{\mathrm{NS}}$ & $118,43^{\mathrm{NS}}$ & $2583,09^{\mathrm{NS}}$ \\
\hline Monsoy 8001 & $66,37^{\mathrm{b}}$ & $2,14^{\mathrm{NS}}$ & $114,97^{\mathrm{NS}}$ & $2773,40^{\mathrm{NS}}$ \\
\hline Média geral & 83,35 & 2,24 & 129,65 & $3.065,03$ \\
\hline C.V. $\%$ & 16,19 & 9,25 & 17,22 & 10,84 \\
\hline DMS & 38,89 & 0,59 & 64,35 & 958,16 \\
\hline
\end{tabular}

observados para as cultivares CD $202(2,04)$; CD 214RR $(1,98)$ e Monsoy $8001(2,10)$. Com relação à produtividade agrícola de grãos, CD 202 e CD 208 foram estatisticamente iguais e significativamente superiores às cultivares BRS CharruaRR, CD 219RR e Monsoy 8001 (Tabela 9).

A classe textural que obteve a maior produtividade foi a $\mathrm{LVe}-4$, de maior gradiente textural e equilíbrio químico de fertilidade, além dos melhores teores foliares, corroborando com Santos (2008), que também observou que o gradiente textural tem influência no rendimento produtivo da soja, principalmente nos anos em que as condições climáticas forem desfavoráveis, caso deste experimento.

Ficou evidente também que o potencial produtivo de solos de textura média (LVe-2) é semelhante aos solos com classe textural argilosa (LVe-4) desde que equilibrados nutricionalmente.

Da mesma forma que a absorção foliar de nutrientes, os resultados dos componentes de produção demonstram grande variabilidade entre as cultivares, inferindo-se que para cada ambiente de produção ocorrem interações entre os genótipos e as classes texturais de solo. Por esta razão, em alguns ambientes de produção analisados, foram observadas diferenças significativas 
entre os parâmetros relativos aos componentes de produção da planta (LVe-2 e LVe-4), enquanto no LVe-3 não se observou tais diferenças.

$\mathrm{O}$ fato de uma determinada cultivar apresentar maior número de vagens formadas por planta não implica necessariamente na obtenção de maior produtividade, pois há que se considerar que outros fatores presentes no ambiente de produção, tais como insetos pragas, doenças e excesso ou deficiência hídrica podem causar chochamento de algumas vagens ou redução da matéria seca acumulada na forma de grãos, impedindo consequentemente, a expressão do máximo potencial produtivo da cultivar Câmara (1998).

Por outro lado existindo boa granação das vagens há que se considerar que, havendo maior número de vagens formadas por planta, haverá maior número de sementes ou de grãos formados na mesma planta. Entretanto, maior será a competição entre os grãos de uma mesma planta perante a mesma quantidade de fatores da produção presentes em um mesmo ambiente de produção. Isto resultará em grãos mais leves, de maneira que, maior número de grãos por planta ou grãos mais pesados formados por planta nem sempre se reflete em maior produtividade agrícola de grãos Câmara (1998).

Estas considerações são importantes e ajudam a compreender a variabilidade de resultados e a eventual ausência de correlação direta entre os componentes de produção da planta e a respectiva produtividade agrícola obtida pela cultivar.

\section{CONCLUSÃO}

A cultivar CD 202 de ciclo precoce foi a mais produtiva em duas classes texturais: Latossolo Vermelho Eutrófico textura média e Latossolo Vermelho textura muito argilosa.
Para a classe textural do Latossolo Vermelho Eutrófico textura argilosa não houve diferença significativa para número de grãos por vagem, peso de mil grãos e produtividade entre as cultivares.

Considerando-se as três classes texturais, as cultivares CD 202, CD 208 e BRS 239 apresentam melhor estabilidade produtiva e maior produtividade média.

Independente da classe textural, a fertilização e manutenção de médios a altos teores de nutrientes nos Latossolos Vermelhos Eutróficos de textura média a muito argilosa possibilita a expressão fenotípica de altas produtividades agrícolas de grãos pelas cultivares de soja.

\section{REFERÊNCIAS BIBLIOGRÁFICAS}

ALLIPRANDINI, L. F.; TOLEDO J.F.F.; FONSECA JR, N S.; ALMEIDA, L.A.; KIIHL, R.A.S. 1994. Efeitos da interação $\mathrm{X}$ ambiente sobre a produtividade da soja no Estado do Paraná. Pesquisa Agropecuária Brasileira, Brasília, v. 29, n. 9, p. 14331444.

ALLIPRANDINI, L. F.; TOLEDO, J.F.F.; FONSECA JR, N.S.; KIIHL, R.A.S.; ALMEIDA, L. A. 1993. Ganho genético em soja no Estado do Paraná, via melhoramento no período de $\mathbf{1 9 8 5 / 8 6}$ a 1989/90. Pesquisa Agropecuária Brasileira, Brasília, v. 28, n. 4, p. 489497.

ANAND, S. C.; Torrie, J. H., 1963. Heritability of yield and other traits and interralationships among traits in the $\mathrm{F}_{3}$ and $\mathrm{F}_{4}$ generations of three soybean crosses. Crop Science, Madison, v. 3, n.6, p.508-511.

ARANTES, N. E., 1979. Interação genótipo $x$ ambiente $e$ estudo de alternativas para seleção da variedade 
de soja (Glycine Max (L.) Merrill), com base em testes regionais. 1979. 51p. Dissertação (Mestrado em Agronomia) Universidade federal de Viçosa- UFV, Viçosa.

BRASIL. 2009. Ministério da Agricultura. Regras para análise de sementes. Brasília. Mapa/ACS, 399 p.

BORKERT, C.M.; SFREDO, G. J.; SILVA, D. N., 1993. Calibração de potássio trocável para soja em Latossolo Roxo distrófico. Revista Brasileira de Ciência do Solo, Viçosa, v. 17, p. 223226.

BORKERT, C. M.; SILVA, D. N.; SFREDO, G. J., 1993. Calibração de potássio nas folhas de soja em Latossolo Roxo distrófico. Revista Brasileira de Ciência do Solo, Viçosa, v. 17, p. 227230.

CÂMARA, G. M. S., 1998. Desempenho produtivo dos cultivares de soja IAC17, IAC-12 e IAC-19, semeados em três épocas de semeadura e em cinco densidades de plantas. Tese de Livre Docência. 165 p. ESALQ/USP. Piracicaba-SP.

CÂMARA, G. M. S. BLACK, R. J.; PAGOT, L.A.; PIMENTEL, F. L.; AZEVEDO FILHO, A. J. B. V.; HEIFFIG, L. S.; JEZOVESK, G.K.; FERREIRA, B.S.C.; OLIVEIRA, L. J.; CHRISTOFFOLETI, P. J.; MEDEIROS, D.; MONQUERO, P.A.; PASSINI, T.; YORINORI, J. T.; PIO, L.C.; LUZ, P. H. C.; LANTMANN, A. F.; CASTRO, L.; SFREDO, G. J.; PEREIRA, L.R.; MAÇÃS, J. E. S.; VITTI, G.C.; TREVISAN, W.; MOLIN, J. P.; ZIVIANI, A. C.; RIBEIRO, T. R. C.; TAMANI, R. P.; KILPP, A. R.
2000. Soja: Tecnologia da Produção II. Piracicaba:ESALQ.

CASTRO, L. P., 2008. Herança da produção de grãos e dos componentes de produção em soja. 44 p. Dissertação (Mestrado) Universidade de São Paulo ESALQ/ USP. Piracicaba-SP.

COOPER, R. L., 2003. Pesquisa sobre produtividade máxima da soja nos E.U.A. Piracicaba: Potafos(Informações Agronômicas $\mathrm{n}^{\circ}$ 101).

CONAB. 2011. Companhia Nacional de Abastecimento. Acompanhamento de safra brasileira: grãos. Brasília, 2011, $38 \mathrm{p}$.

EMBRAPA. 2006. Sistema brasileiro de classificação de solos. 2.ed. Rio de Janeiro: Embrapa Solos. EMBRAPA. 2008. Tecnologia de Produção de Soja - Região Central do Brasil - 2009 e 2010. Londrina: Embrapa Soja: Embrapa Cerrado: Embrapa Agropecuária Oeste.

FAGEROA, N.K.; STONE, L.F; SANTOS, A.B. Maximização da eficiência de produção das culturas. Brasília, Embrapa Comunicação para Transferência de tecnologia; Santo Antônio de Goiás, Embrapa Arroz e feijão, 19, 294 p.

FEHR, W. R.; CAVINESS, C. 1977. Stages of soybean development. Ames, Yowa: Yowa State University, Cooperative Extension Service, 11 p. (Special Report, 80).

FIETZ, C. R.; FISCH, G. F. 2008. O Clima na região de Dourados - MS. Dourados -MS: Embrapa Agropecuária Oeste, $32 \mathrm{p}$. 
GIECO, J. O. 1997. Interação genótipo x ambientes e implicações para o melhoramento da soja. 98 p. Dissertação (Mestrado em Genética e Melhoramento de Plantas) Universidade de São Paulo - ESALQ-USP, Piracicaba-SP.

HEIFFIG, L. S. 2002. Plasticidade da cultura da soja (Glycine max (L.) Merril) em diferentes arranjos espaciais. 2002. 85 p. Dissertação (Mestrado). Universidade de São Paulo -ESALQ-USP,Piracicaba-SP.

JUNIOR, H.M.; COSTA, J. A. 2002. Contribuição relativa dos componentes do rendimento para produção de grãos de soja. Pesquisa Brasileira Agropecuária. Brasília - DF. p. 269274.

KIEHL, R. A. S. 2006. Como recolocar a "locomotiva" nos trilhos?. Piracicaba SP: ESALQ-USP. p. 4. (Visão Agrícola - Soja. $n^{\circ}$ 5).

LAÍNEZ-MEJÍA, J. R. 1996. Implicações genótipos $x$ ambientes na seleção de progênies de soja com ênfase nas produtividades de grãos e óleo. Piracicaba. 145 p. Tese (Doutorado em Genética e Melhoramento de Plantas) Universidade de São Paulo - ESALQUSP, Piracicaba-SP.

MALAVOLTA, E.; VITTI, G. C.; OLIVEIRA, S.A. 1997. Avaliação do estado nutricional das plantas princípios e aplicações. 2.ed. 319 p. Piracicaba: Potafos.

MALAVOLTA, E. 2006. Manual de nutrição mineral de plantas. São Paulo: Editora Agronômica-Ceres. 638 p.
MOTTA, I. S.; BRACCINI, A. L., SCAPIM, C. A.; GONÇALVES, A. C. A; BRACCINI, M. C. L. 2000. Características agronômicas e componentes da produção de sementes de soja em diferentes épocas de semeadura. Revista Brasileira de Sementes, p.153-162.

NOVAIS, R. F. LOPES, A. S.; GUILHERME, L. R. G.; MEURER, E. J. DECHEN, A. R.; NACHTIGALL, G. R.; MELLO, J. W. V.; SOUSA, D. M. G.; MIRANDA, L. N.; OLIVEIRA, S. A.; SILVA, I. R.; MENDONÇA, E. S.; CANTARELLA, H.; SMYTH, T. J.; NUNES, F. N.; ERANANI, P.R.; ALMEIDA, J. A.; SANTOS, F. C.; ALVARES, V. H. V.; ROSCOE, R.; KURIHARA, C. H.; ABREU, C. A.; GRABIELLI, G. C.; ALCARDE, J.C.; CANTARUTTI, R. B.; BARROS, N. F.; PRIETTO, H. E.; CERETTA, C.A.; SILVA, L. S.; PAVINATO, A.; ANGHINONI, I.; FREIRE, M. B. G. S.; FREIRE, F. J.; DIAS, L. E.; FRANCO, A. A.; CAMPELLO, E. F.C.; GOEDERT, W. J.; OLIVEIRA, S.A. 2007. Fertilidade do Solo. Viçosa, MG; Sociedade Brasileira de Ciência do Solo. $1017 \mathrm{p}$.

OLIVEIRA, J. B. de. 2008. Pedologia aplicada. 3.ed. Piracicaba: FEALQ. 592 p.

PARRA, J. R. P. 2006. Visão Agrícola. Piracicaba: ESALQ - USP, 6 p. (Soja. $\mathrm{n}^{\mathrm{o}} 5$ ).

PRADO, H.do. 2004. Classes das condições químicas superficiais para manejo. In: FERTIBIO. Anais 1. CD-ROM.

PRADO, H,do. 2010. Pedologia fácil: Curiosidade: Sentidos. Disponível 
em:<www.pedologiafacil.com.br>.

Acesso em: 10 de maio de 2010.

PRADO, H.. 2008. Pedologia fácil: aplicação na agricultura. 2.ed. Piracicaba. 145 p.

RAIJ, B. V. 1991. Fertilidade dos solo e adubação. Piracicaba. São Paulo: Ceres, Potafos. 343 p.

RAIJ, B. V. 1997. Recomendações de adubação e calagem para o estado de São Paulo. Campinas: Instituto Agronômico. 285 p. (Boletim Técnico, 100).

REIS, E.F.; REIS, M. S.; SEDIYAMA, T.; CRUZ, C. D. 2002. Estimativa de variância e herdabilidade de algumas características primárias e secundárias da produção de grãos de soja (Glycine $\max$ (L.) Merrill). Ciência e Agrotecnologia, Lavras - MG, v. 26, n. 2 p. 749-761.

RICHART, A.; LANA, M.C.; SCHULZ, L.R.; BERTONI, J.C.; BRACCINI, A.L. 2006. Disponibilidade de fósforo e enxofre para a cultura da soja na presença de fosfato natural reativo, superfosfato triplo e enxofre elementar. Revista Brasileira de Ciência do Solo, Viçosa, v. 30, n. 4, p.695-705.

ROCHA, M. de M.; VELLO, N. A., 1999. Interação genótipo e locais para rendimento de grãos de linhagens de soja com diferentes ciclos de maturação. Bragantia, Campinas, v. 58, n. 1, p. 6981.

SANTOS, F. C. dos; NOVAIS, R. F.; NEVES, C. L.; FOLONI, J. M. ALBURQUERQUE FILHO, M. R.; KER, J. C. 2008. Produtividade e aspectos nutricionais de plantas de soja cultivadas em solos de cerrado com diferentes texturas. Revista Brasileira de Ciência do Solo, Viçosa, v. 32, p. 2015-2025.

SEDIYAMA, T.; VIANA, A. A. N., NOGUEIRA, A. P. Q.; SILVA, A. A.; REIS, C.; MACEDO, D. M.; DETMANN, E.; MORAIS, E. G. H.; FINOTO, E. L.; TRANCREDI, F. D.; FERNANDES, F. L.; BARROS, H. B.; SEDIYAMA, H. A.; MENDONÇA, H. L.; DONZELE, J. L. HENRIQUES, L. T.; PICANÇO, M. C.; TOLEDO, M. R.; RAMOS, M. M.; ODA, M. C,.; PAULINO, M. F.; ABREU, M. L. T.; CAMPOS M. R.; PEREIRA, O. G.; .; DHINGRA, O. D.; PARIZZI, P.; TEIXEIRA, R. C.; OLIVEIRA, R. F. M.; OLIVEIRA, P. A.; FILHO, S. C. V.; CAMPOS, S. R. F.; XAVIER, U. M.; MACHADO, V. L. S.; AZEVEDO, Z. M. M. 2009. Tecnologia de produção e usos da soja. Londrina: Mecenas.

SOLDINI, D. O. 1993. Interação genótipos $x$ locais e correlações entre caracteres com ênfase na produtividade de óleo em soja. Piracicaba. 136 p. Dissertação (Mestrado em Genética e Melhoramento de Plantas) Universidade de São Paulo ESALQ-USP, Piracicaba-SP.

TOLEDO, J. F. F.ALLIPRANDINI, L. F.; FONSECA JR, N. S.; KIIHL, R. A. S.; ALMEIDA, L. A. 1990. Ganho genético em soja no Estado do Paraná via melhoramento. Pesquisa Agropecuária Brasileira, Brasília, v. 25, p. 89-94.

TROEH, F. R.; Thompson, L. M. 2007. Solos e Fertilidade do Solo. 6.ed. São Paulo: Andrei, 718 p. 